\author{
Lucjan Janas \\ Politechnika Rzeszowska \\ ljanas@prz.edu.pl
}

DOI: 10.35117/A_ENG_16_05_05

\title{
Laboratory tests of the prototype tram rails vibroisolation
}

\begin{abstract}
The article presents the results of prototype vibroisolation of tram rails, made from used tires, as an embedded rail system. Static and dynamic stiffness of the proposed vibroisolation were determined. The effect of temperature on the change of the stiffness was presented. Dynamic stiffness is given for the different frequency of load. The impact of fatigue loads on the parameters of the system was also presented.
\end{abstract}

Keywords: Railways; Vibroisolation; Embedded rail; Laboratory tests

\section{Introduction}

It is known that vibroisolation in railways is used to reduce noise and protect against vibration buildings and people in the buildings. Vibroisolation increases also the stability of the track and reduces pressure on the ground. Vibroisolation materials are usually necessary for the railway network and in particular for tram tracks.

A proper selection of vibroisolation parameters allows to minimize the harmful effects of rail traffic on environment, while it is important to parameters of the applied material do not undergo significant changes over time. The current procedures of laboratory tests are criticized [2], and more and more attention is paid to fatigue and stiffness tests, in various, and especially low temperatures.

This work presents some research results of a prototype vibroisolation of tram rails intended for use in embedded rails system, manufactured by the company Mostostal-Warszawa. The new material should play not only the function of reducing vibration and noise, but also contribute to waste, because it was designed from recycled and worn out car tires. The study was performed in the Divisional Structures Laboratory at the Faculty of Civil Engineering, Environmental Engineering and Architecture University of Rzeszów. The laboratory also tested vibroisolation in the form of rail soleplates. The results were discussed, among others, in [1].

\section{Description of tested material}

The main component of tested vibroisolation was rubber pellets obtained from recycling worn out car tires. A view of the sample ready for testing is shown in Fig. 1. The particle size of the pellets ranged $1 \div 4 \mathrm{~mm}$, determination of particle size distribution of the rubber granules is given in Table 1. Polymer granules were used as a binder resin. The amount of resin used was selected in such a manner to cover the external surfaces of the grains and after binding, to form coherent structure resistant to external loads. 

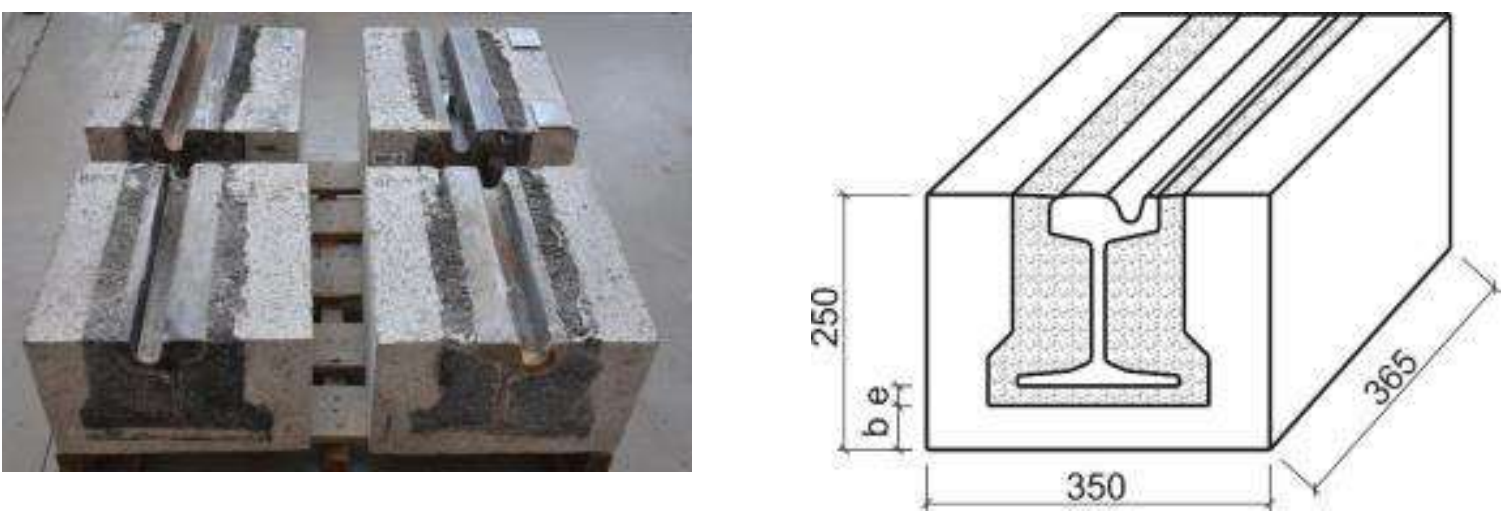

1. View and dimensions of samples for testing

Table 1. Granulometric composition of the rubber granulate sample [1]

\begin{tabular}{|c|c|c|c|}
\hline Fraction [mm] & Mass [g] & $\begin{array}{c}\text { Contribution } \\
{[\mathbf{\%}]}\end{array}$ & Selection [\%] \\
\hline $5.6 \div 5$ & 0 & 0 & 0 \\
\hline $5 \div 4$ & 3.9 & 1.86 & 1.86 \\
\hline $4 \div 2$ & 197.2 & 93.82 & 95.67 \\
\hline $2 \div 1$ & 8.8 & 4.19 & 99.86 \\
\hline $1 \div 0.3$ & 0.1 & 0.05 & 99.90 \\
\hline $0.3 \div 0.125$ & 0.1 & 0.05 & 99.95 \\
\hline $0.125 \div 0.063$ & 0.1 & 0.05 & 100 \\
\hline$<0.063$ & 0 & 0 & 100 \\
\hline Sum: & 210.2 & 100.00 & - \\
\hline
\end{tabular}

A homogeneous mixture of the granules and resin was laid in steel molds in which previously rail was placed, and properly concentrated. The forms filled with the plastic mass were heated to accelerate the crosslinking of the resin. Then embedded rail was placed in a larger form and concreted. In this way, test pieces were prepared. The production technology was analogous to the planned technology of actual track section.

The basic geometrical parameters of the samples are given in the Table. 2. Before the tests, the samples were tested for the presence of any scratches, cracks or delamination. Damages of such types were not found.

Table 2. Comparison of tested samples

(e - is the thickness of the elastomer under the presser foot)

\begin{tabular}{|c|c|c|c|c|}
\hline $\mathrm{Nr}$ & Sample & $\begin{array}{c}\text { Elastomer's thick- } \\
\text { ness „,e, }\end{array}$ & $\begin{array}{c}\text { Elastomer's thick- } \\
\text { ness „,e”, }\end{array}$ & $\begin{array}{c}\text { Average thickness } \\
\text { „e" }\end{array}$ \\
\hline$[-]$ & {$[-]$} & {$[\mathrm{mm}]$} & {$[\mathrm{mm}]$} & {$[\mathrm{mm}]$} \\
\hline 1 & B1 & 31.0 & 29.0 & 30.0 \\
\hline 2 & B2 & 30.0 & 31.0 & 30.5 \\
\hline 3 & B2-1 & 35.0 & 38.0 & 36.5 \\
\hline 4 & B2-2 & 32.0 & 30.0 & 31.0 \\
\hline 5 & BP-1 & 23.5 & 25.5 & 24.5 \\
\hline 6 & BP-2 & 26.0 & 26.0 & 26.0 \\
\hline 7 & BP2-1 & 25.0 & 30.0 & 27.5 \\
\hline 8 & BP2-2 & 30.0 & 30.0 & 30.0 \\
\hline 9 & BP2-3 & 31.0 & 35.0 & 33.0 \\
\hline
\end{tabular}




\section{Study of static stiffness}

The study was performed on a properly prepared stand - Fig. 2. The load was applied by actuator Instron-Schenck Class 1. Deformation of the samples was measured by sensor of displacements HBM on the measurement basis of $20 \mathrm{~mm}$.

The study was conducted according to the manufacturer's guidelines, in accordance with the procedure described in [3]. Each sample was loaded and unloaded six times in a range from $0.5 \mathrm{kN}$ to $85 \mathrm{kN}$. A load speed was $50 \mathrm{kN} / \mathrm{min}$. Vertical displacements of track were recorded during the last cycle. Next, the vertical stiffness was calculated between 5 and $80 \mathrm{kN}$, using the formula:

$$
\mathrm{K}_{80}=\frac{75}{\mathrm{~d}}[\mathrm{kN} / \mathrm{mm}]
$$

where: $\mathrm{d}$ - average rail displacement between 5 and $80 \mathrm{kN}$ load.

In addition, similarly was determined the value of stiffness in the range of loads 5-40 $\left(\mathrm{K}_{40}\right), 5-30 \mathrm{kN}\left(\mathrm{K}_{30}\right)$ and $5-14 \mathrm{kN}\left(\mathrm{K}_{14}\right)$.
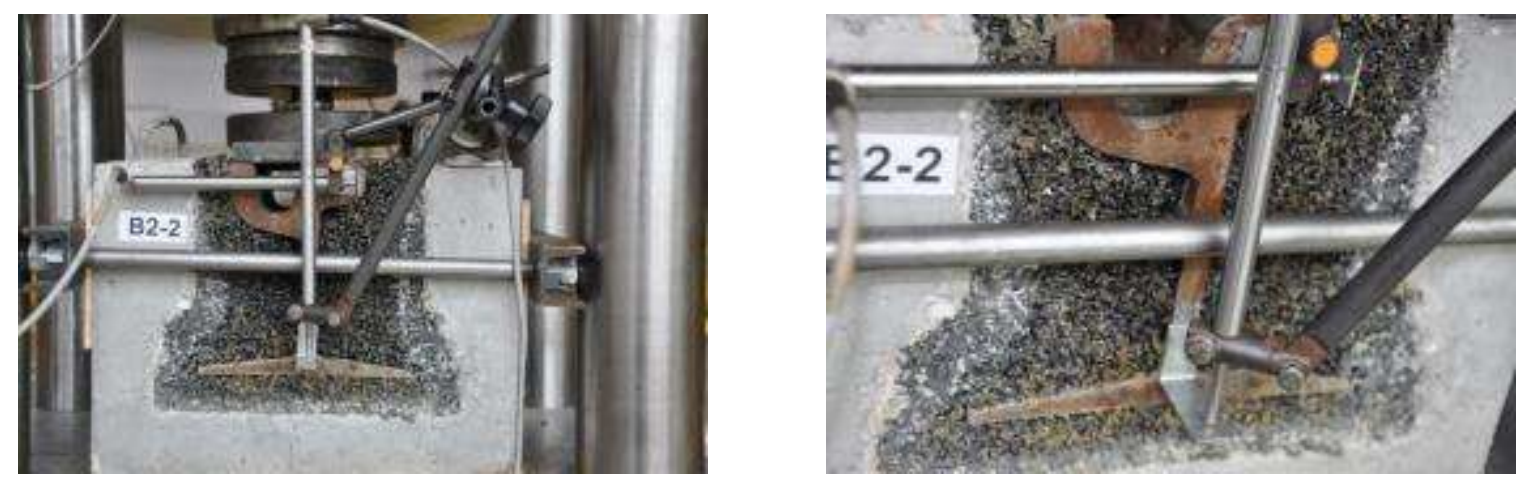

2. View of test stand

The static stiffness and stiffness of samples of $1 \mathrm{mb}$ system, determined in the temperature $23^{\circ} \mathrm{C}$, is shown in the Table 3 .

Table 3. Vertical static stiffness

\begin{tabular}{|c|c|c|c|c|c|c|c|c|c|}
\hline \multirow{2}{*}{$\mathbf{N} \mathbf{*}$} & \multirow{2}{*}{ Sample } & \multicolumn{6}{|c|}{ Vertical static stiffness [kN/mm] } \\
\cline { 3 - 10 } & & \multicolumn{2}{|c|}{$\mathbf{K}_{\mathbf{8 0}}$} & \multicolumn{2}{|c|}{$\mathbf{K}_{\mathbf{4 0}}$} & \multicolumn{2}{|c|}{$\mathbf{K}_{\mathbf{3 0}}$} & \multicolumn{2}{|c|}{$\mathbf{K}_{\mathbf{1 4}}$} \\
\hline$[-]$ & {$[-]$} & Sample & $1 \mathrm{mb}$ & Sample & $1 \mathrm{mb}$ & Sample & $1 \mathrm{mb}$ & Sample & $1 \mathrm{mb}$ \\
\hline 1 & B1 & 10.64 & 30.40 & 8.62 & 24.63 & 8.55 & 24.43 & 9.17 & 26.20 \\
\hline 2 & B2 & 12.10 & 34.57 & 9.84 & 28.11 & 9.87 & 28.20 & 11.26 & 32.17 \\
\hline 3 & B2-1 & 18.15 & 51.86 & 17.63 & 50.37 & 18.48 & 52.80 & 21.18 & 60.51 \\
\hline 4 & B2-2 & 15.89 & 45.40 & 15.17 & 43.34 & 15.75 & 45.00 & 17.93 & 51.23 \\
\hline 5 & BP-1 & 21.43 & 61.23 & 19.74 & 56.40 & 19.98 & 57.09 & 21.08 & 60.23 \\
\hline 6 & BP-2 & 33.97 & 97.06 & 31.56 & 90.17 & 30.56 & 87.31 & 27.69 & 79.11 \\
\hline 7 & BP2-1 & 11.58 & 33.11 & 9.23 & 26.37 & 9.19 & 26.26 & 10.48 & 29.97 \\
\hline 8 & BP2-2 & 18.47 & 52.77 & 18.79 & 52.83 & 19.81 & 56.60 & 22.84 & 65.26 \\
\hline 9 & BP2-3 & 10.0 & 28.57 & 7.84 & 22.40 & 7.69 & 21.97 & 8.44 & 24.11 \\
\hline
\end{tabular}


Disruption of the elastomer from the rail was reported during the static tests (Fig. 3). In addition, scratch (rupture) occurred at the base sample of the series BP.

a)

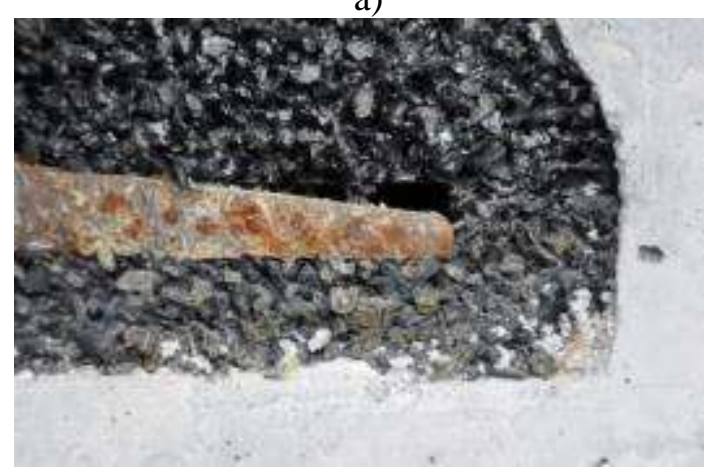

b)

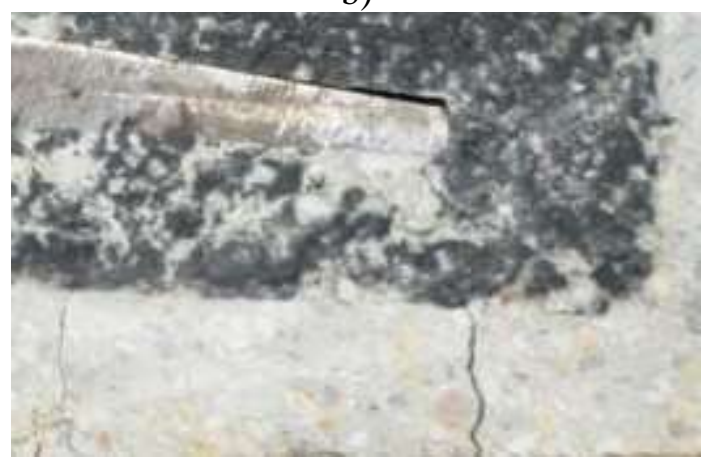

3. Disruption of the elastomer from the rail foot during the examination of the static vertical stiffness: a) the sample of series B, b) the sample of series BP

Static stiffness was measured at room temperature $(23 \pm 5)^{\circ} \mathrm{C}$ and temperatures $0 \pm 3^{\circ}$ $\mathrm{C},-10 \pm 3^{\circ} \mathrm{C},-20 \pm 3^{\circ} \mathrm{C}$. The samples were cooled in a freezer, which was next to the test place. Before each test, the samples were stored at low temperature for minimum 16 hours. Sample results are shown in Fig. 4.
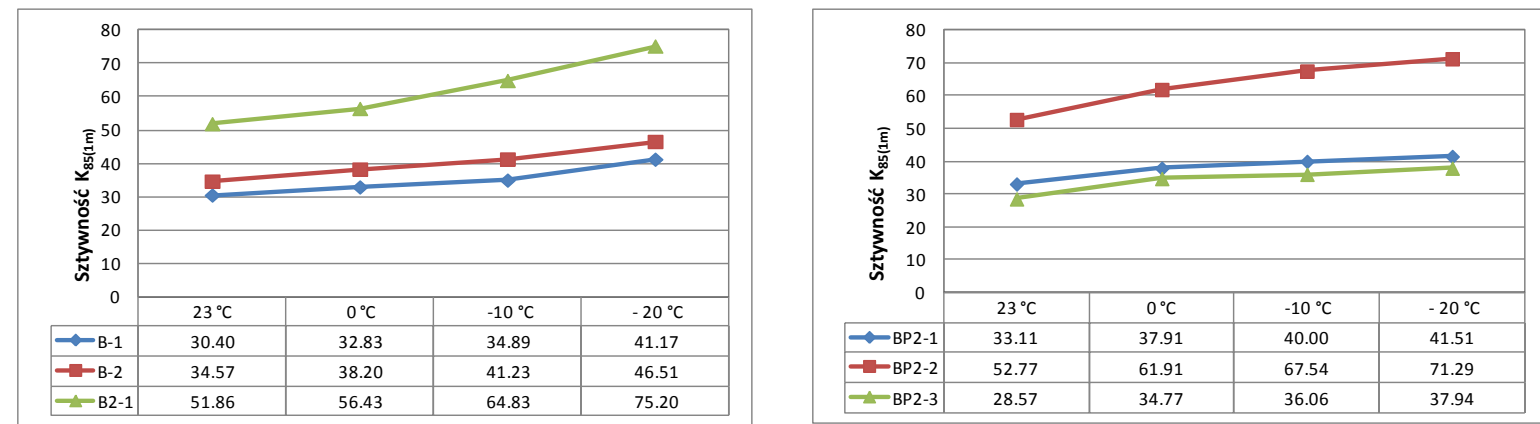

4. Static stiffness $\mathrm{K}_{80}$ of samples from series $\mathrm{B}$ and BP depending on the temperature

Studies have shown that temperature significantly influences the static stiffness of the tested material. The drop in temperature from +23 to $-20^{\circ} \mathrm{C}$ changes the stiffness by 25 to $45 \%$.

\section{Studies of dynamic stiffness}

Samples were subjected to cyclic loading at the minimum $\mathrm{F}_{2}=5 \mathrm{kN}$ and maximum value $\mathrm{F}_{1}=35 \mathrm{kN}$, for 1000 cycles. Load was applied with frequencies: 0.5, 1.0, 4.0 and 5.0 Hz. During the tests, the force and displacement were recorded and the dynamic stiffness was calculated based on the last 100 cycles, using the formula:

$$
\mathrm{K}_{\mathrm{d}(1.25)}=\frac{\mathrm{F}_{1}-\mathrm{F}_{2}}{\mathrm{~d}_{1}-\mathrm{d}_{2}}[\mathrm{kN} / \mathrm{mm}]
$$

where: $d_{1} i d_{2}$-averaged values of vertical track displacement corresponding to the maximum $\mathrm{F}_{1}$ and minimum $\mathrm{F}_{2}$ force.

Dynamic stiffness of samples at the frequency of $4 \mathrm{~Hz}$, determined at $+23^{\circ} \mathrm{C}$ is shown in Table 4. 
Table 4. Dynamic stiffness of samples at the frequency of $4 \mathrm{~Hz}$ and temperature $+23^{\circ} \mathrm{C}$

\begin{tabular}{|c|c|c|c|}
\hline \multirow{2}{*}{ Nr } & \multirow{2}{*}{ Sample } & \multicolumn{2}{|c|}{ Dynamic stiffness $\mathbf{K}_{\mathbf{d}}[\mathbf{k N} / \mathbf{m m}]$} \\
\cline { 3 - 4 } & & $\begin{array}{c}\text { Sample with length } 0.35 \\
\mathrm{~m}\end{array}$ & $1 \mathrm{mb}$ of system \\
\hline 1 & B1 & 13.35 & 38.14 \\
\hline 2 & B2 & 17.08 & 48.80 \\
\hline 3 & B2-1 & 28.93 & 82.66 \\
\hline 4 & B2-2 & 27.20 & 77.71 \\
\hline 5 & BP-1 & 34.13 & 97.51 \\
\hline 6 & BP-2 & 49.75 & 142.14 \\
\hline
\end{tabular}

Dynamic stiffness in dependence on temperature and frequency is shown in Fig. 5.
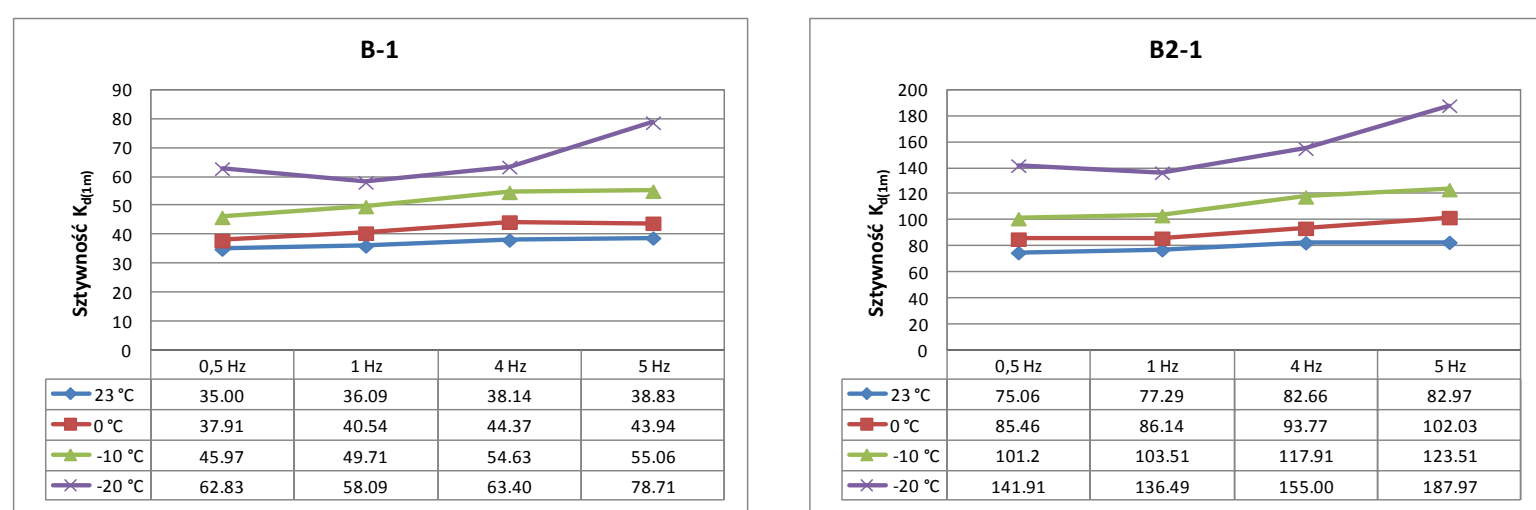

5. Dynamic stiffness of samples B-1 and B2-1 in dependence on temperature and frequency

Dynamic stiffness, of course, varies for different load frequencies. The stiffness varies largely with temperature. In the range of +23 to $-20^{\circ} \mathrm{C}$, the dynamic stiffness changes even twofold.

\section{Fatigue tests}

To check the durability of rails embedded system, we conducted fatigue tests. The study consisted in the repetition of the load with the constant amplitude for a period of three million cycles. The angle of inclination of the load was $22^{\circ}$ relative to the axis of the neck. We applied sinusoidal alternating load in the range from $5 \mathrm{kN}$ to $50 \mathrm{kN}$ at $5 \mathrm{~Hz}$. The test procedure was as follows:

a) studies of static and dynamic stiffness before the load,

b) fatigue load with 3 million cycles,

c) the study of static and dynamic stiffness after fatigue loading.

In the study, we used a hydraulic actuator in the range $\pm 100 \mathrm{kN}$ and four inductive sensors, two with the range $\pm 10 \mathrm{~mm}$ to register the horizontal movement of the rail head, and two with the range $\pm 5 \mathrm{~mm}$ for the vertical movement of the rail foot. The test place is shown in Fig. 6. 


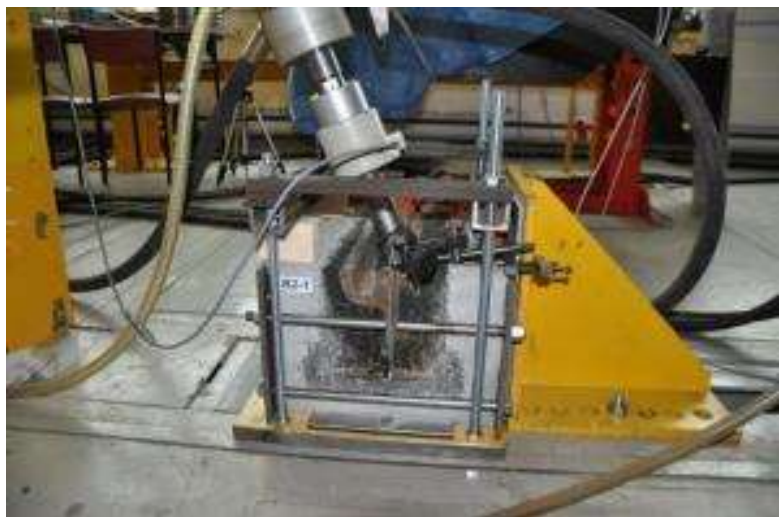

6. Test place for fatigue tests

The dynamic displacement of the rail head and foot with respect to the concrete block was measured during the first and last thousand cycles for at least one cycle. Fig. 7 shows a typically damaged samples occurring after about 5 thousand load cycles after the test. These damages were primarily detachments of vibroisolation loosening material from the rail.

a)

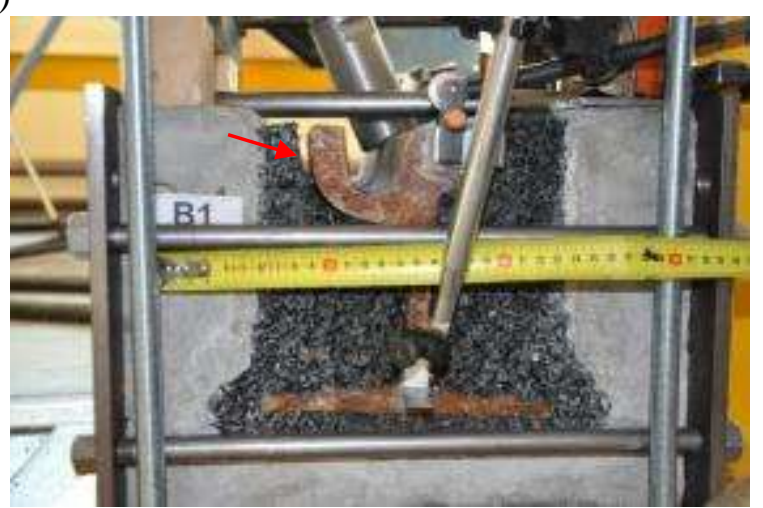

b)

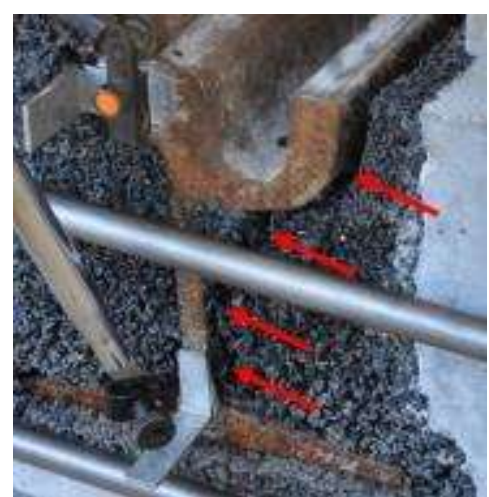

7. View of damage of sample from B series: a) detachment of the rail head from the elastomer after 5 thousand of cycles, b) detachment from the head and neck after 3 million of cycles

Examples of results of fatigue testing in the form of displacements before and after 3 million of cycles are shown in Figs. 8 and 9. The variation in the stiffness is presented in Fig. 10.

a)

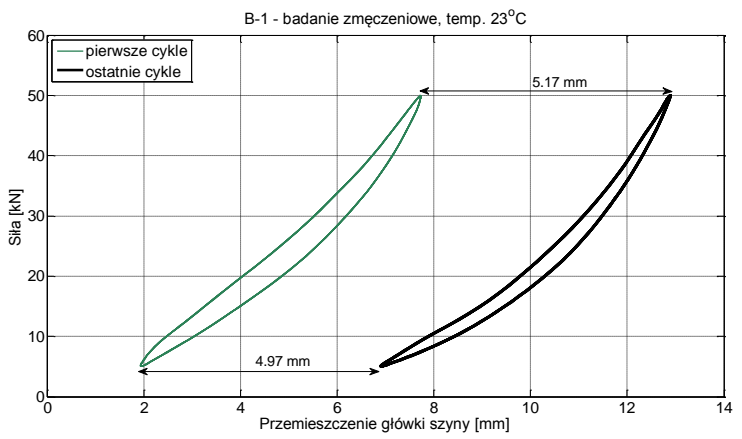

b)

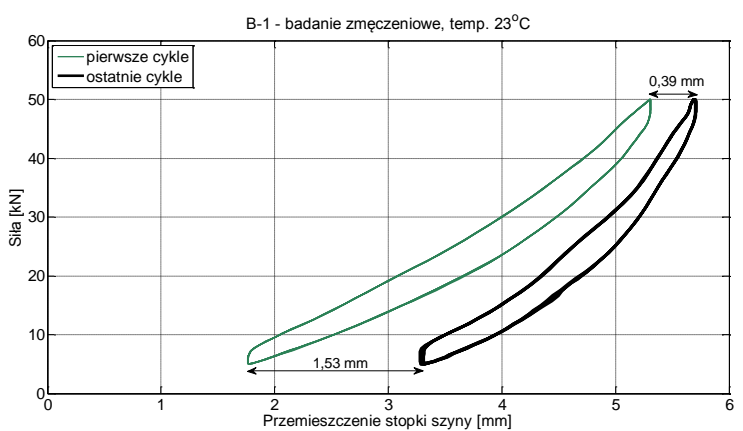

9. The result of fatigue test of sample B-1: a) horizontal displacement of the rail head, b) vertical displacement of the rail foot 
a)

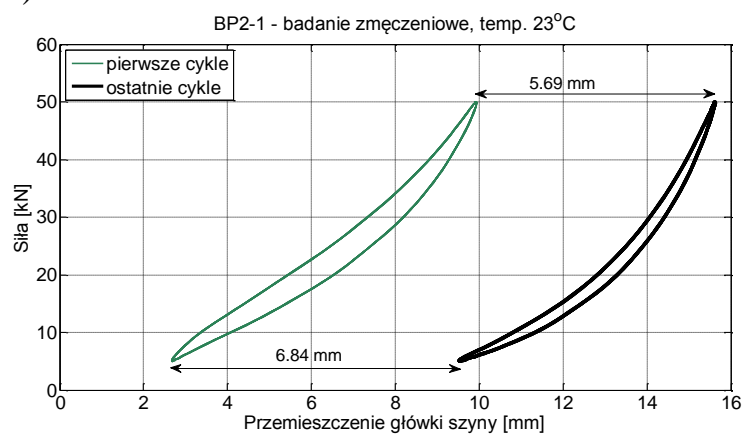

b)

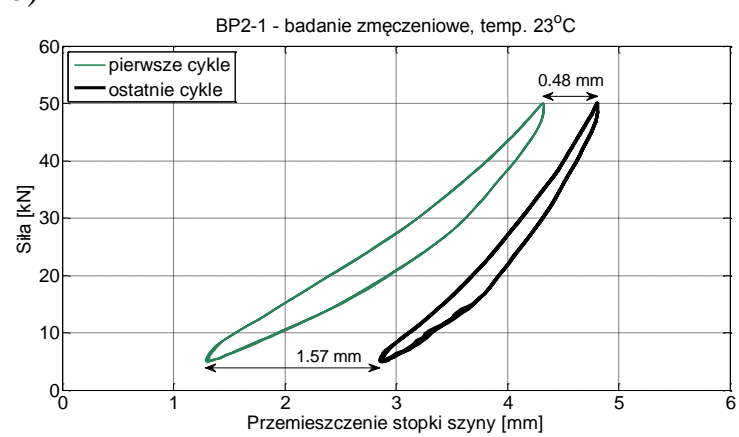

9. The result of fatigue test of sample BP2-1: a) horizontal displacement of the rail head, b) vertical displacement of the rail foot

a)

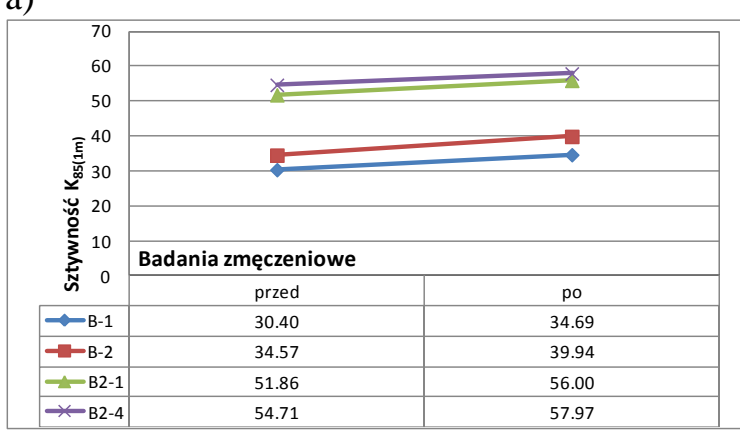

b)

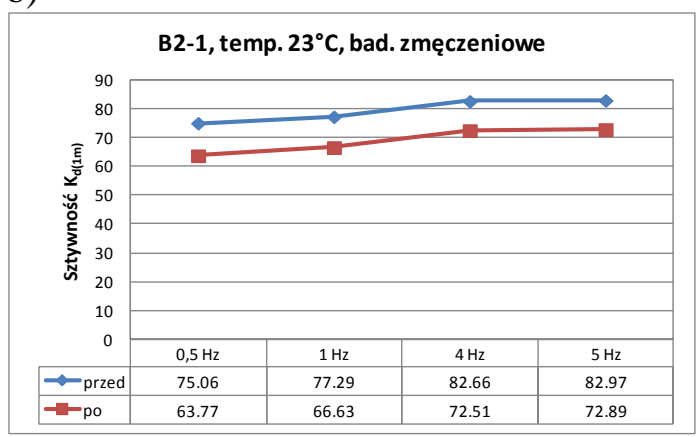

10. Static (s) and dynamic (b) stiffness of samples before and after fatigue loading

The fatigue load caused the displacement of the rail with the order of $6 \mathrm{~mm}$ in the horizontal direction and 0.5 to $1.7 \mathrm{~mm}$ in the vertical direction. Static and dynamic stiffness increased after the fatigue sample up to $20 \%$.

\section{Conclusions}

The presented results refer to a prototype vibroisolation of tram rails made in the embedded system. The use of material obtained from the recycling of worn out car tires is a big advantage of the proposed solution. The results allow concluding that the parameters of the material are so appropriate. Therefore, it is worth to continue further research.

The proposed system significantly alters its parameters under the influence of temperature. The static stiffness varies up to $45 \%$, and dynamic stiffness even twice.

Fatigue load changes relatively little static and dynamic stiffness. However, we found detachment of the material, significant displacements of the rail and damages that can reduce the life of the system and shorten its lifetime. Cracks and fissures between the rail and the material vibroisolation appear relatively quickly.

The experience of the manufacturer partly confirmed in the above tests show that it is relatively easy to modify the properties of the proposed material. On one hand, it is a beneficial feature of such technology because it allows selecting parameters according to needs. On the other hand, the lack of production control (no testing of individual batches) can cause large discrepancies between the expected and received parameters.

The need for research, including studies mainly in low temperatures and fatigue testing concerns not only innovative prototype solutions. Such studies should also be carried out in order to control the parameters of materials already known and used. It should be remembered that the climatic conditions in our country are different than in most Western European countries and new technologies cannot be applied uncritically. 


\section{Source materials}

[1] Janas L., Jurczuk J., Poneta P.: Badania laboratoryjne prototypowych wibroizolacji przeznaczonych do stosowania w nawierzchniach szynowych. Zeszyty Naukowe SITK RP, Oddział w Krakowie nr 2 (101)/2013, s. 121-129.

[2] Kowalska Z.: Badania laboratoryjne przekładek podszynowych w przytwierdzeniach szyn kolejowych według norm CEN, Problemy Kolejnictwa, Zeszyt 152, tom 55/2011

[3] PN-EN 13146-9:2010. Kolejnictwo. Metody badań systemów przytwierdzeń. Część 9: Określenie sztywności. 